\title{
The transcephalic dc potential and disjunctive reaction time performance*
}

\author{
HOWARD FRIEDMAN and HARVEY A. TAUB $\dagger$ \\ Syracuse VA Hospital, Syracuse, N.Y. 13210
}

The relationship between the transephalic dc potential (TCDC) and disjunctive reaction time (RT) in clinically normal male Ss was investigated in three experiments with visual and two experiments with auditory presentation of stimuli. In each experiment, comparisons of those Ss shifting in TCDC in a positive direction vs those shifting negatively and/or less positively were made. In every case, the group of Ss shifting in the relatively more positive direction showed a significant association between TCDC and a change toward slowing of RT performance.

The slowly changing direct current potential, measured fronto-occipitally and designated as the "transcephalic dc potential" (TCDC), was originally conceptualized as a primitive control system (Becker, Bachman, \& Friedman, 1962). It has been found to relate not only to various generalized psychological states (Cowen, 1967a, b, 1968) and to major alterations in states of consciousness (Becker, Bachman, \& Friedman, 1962; Friedman, Becker, \& Bachman, 1962), but also to several more specific parameters as simple psychomotor and discriminatory functioning (Friedman \& Taub, 1969; Friedman, 1972). The latter studies demonstrated that (1) with simple serial reaction time (RT), a TCDC shift in a more positive direction was associated with relatively greater decrements in performance over time than was the case for negatively shifting dc potential, and (2) a replicable association could be obtained between negative TCDC shifters prior to a scotopic critical flicker frequency (CFF) task and performance on that task. These two studies followed from an attempt to elucidate an underlying mechanism through which external force fields, as magnetic radiation, could exert a biological effect, since a previous investigation (Friedman, Becker, \& Bachman, 1967) had indicated that temporary changes occurred in RT performance when low-level modulated fields were applied transversely across the cerebral area.

The current study continues this line of investigation with the anticipation that other more complex psychomotor tasks would also reveal a similar type of relationship with TCDC shift. Thus, disjunctive visual and auditory tasks were utilized with the hypothesis that a greater number of Ss characterized as "positive"

*This study was supported by the Veterans Administration as part of Project 2935-01.

+ Also at the State University of New York Upstate Medical Center, Syracuse, New York. shifters in TCDC would slow up in RT performance over time than would be the case for the "negative" or relatively less "positive" TCDC shifters.

\section{METHOD \\ Subjects}

The Ss were white male clinically normal volunteers between 16 and 30 years of age and without any significant visual or auditory defects. In every case, in the experiments described below, there were no significant age differences in intergroup comparisons.

\section{Procedure}

Five separate experiments were conducted, three using the visual modality and two the auditory.

In Experiment I, each of $48 \mathrm{Ss}, 17-28$ years of age, was seated in a sound- and lightproof chamber with Beckman bipotential electrodes placed in the midline position on the forehead (recording electrode) and immediately above the occiput (reference electrode) and with a ground electrode on the back of a hand. Head electrodes were kept in place by a rubberized bandage. A display panel, approximately $3 \mathrm{ft}$ from the S's eyes, contained a red light 6 in. above a green light. An initial TCDC reading obtained with a Hewlett-Packard dc voltmeter served as a check upon the Beckman Type $\mathrm{R}$ Dynograph, outside the chamber, which continuously recorded the potential. A spring-loaded switch was given to the $S$, who was informed that he was to turn off each light as quickly as possible after its appearance by pushing in one direction for the red light and in the opposite direction for the green light. The chamber lights were then turned off, and six instructional trials were given to acquaint $S$ with the procedure. After a 4-min rest period to accustom $S$ to the minor background illumination, six practice trials were given. $S$ was then informed that the main task would begin. Grason-Stadler programming equipment presented 100 red stimuli and 100 green stimuli in a predetermined random order at the rate of $8 / \mathrm{min}$. Reaction time was recorded in milliseconds by a printout timer. At the end of the task, a final Hewlett-Packard reading was taken. Electrodes were checked for drift, and the very few Ss that exceeded $1 \mathrm{mV}$ of electrode drift during the 30-35-min experimentation period were discarded.

Experiment II, with 35 Ss 18-23 years of age, and Experiment III, with 40 Ss 16-29 years of age, replicated Experiment I, with the exception of using a total of 96 randomized stimuli (48 red and 48 green) presented at a rate of $4 / \mathrm{min}$.

In Experiment IV, with 62 Ss 17-25 years of age, two pure tones were generated, a high at $5,000 \mathrm{~Hz}$ and a low at $2,000 \mathrm{~Hz}$, which were about $85 \mathrm{~dB}$ at the source, a small speaker at the display panel approximately $3 \mathrm{ft}$ from $S$. The general task procedures and TCDC measurements were as described for Experiment I. However, after receiving the six practice trials, $\mathrm{S}$ was also given 10 randomized trials preceded by a "ready" signal. These trials, designated as Part 1 , were deemed necessary because of increased task complexity with the auditory stimuli. Part 2 followed immediately and consisted of 96 randomized stimuli presented without a "ready" signal in the same fashion as the perceptual stimuli in the previous experiments. Overall experimental time was approximately $35 \mathrm{~min}$.

Experiment V, with 54 Ss $17-30$ years of age, replicated Experiment IV, with the exception of having a 20- rather than a 5 -min rest period during which $S$ listened to taped "show"-type music. Overall experimental time was about 50-55 min. 
Table 1

Range of TCDC Shifts for Each Group, Point of TCDC Measurement (from Initial Reading), $\mathrm{N}$, and $\chi^{2}$ Evaluations of Direction of Change in RT Performance

\begin{tabular}{|c|c|c|c|c|c|c|c|c|c|}
\hline & \multicolumn{3}{|c|}{ Prior to Task } & \multicolumn{3}{|c|}{ During Task } & \multicolumn{3}{|c|}{ After Task } \\
\hline & Range (mV) & $\mathrm{N}$ & $x^{2}$ & Range (mV) & $\mathbf{N}$ & $x^{2}$ & Range (mV) & $\mathbf{N}$ & $x^{2}$ \\
\hline \multicolumn{10}{|l|}{ Experiment I } \\
\hline Positive & $+6.5-+32.0$ & 24 & $3.38 *$ & $+11.5-+33.0$ & 24 & $5.04 *$ & $+14.0-+33.0$ & 25 & $5.76 \dagger$ \\
\hline Negative & $+6.0--13.5$ & 24 & n.s. & $+11.0--13.0$ & 24 & n.s. & $+11.0--12.0$ & 23 & n.s. \\
\hline \multicolumn{10}{|l|}{ Experiment II } \\
\hline Positive & $+3.0-+12.0$ & 19 & $3.37 *$ & $+5.5-+15.5$ & 18 & $6.72+$ & $+6.0-+19.0$ & 18 & $9.39+$ \\
\hline Negative & $+2.0--9.5$ & 16 & $3.06 *$ & $+5.0--8.0$ & 17 & n.s. & $+5.5--10.0$ & 17 & n.s. \\
\hline \multicolumn{10}{|c|}{ Experiment III } \\
\hline Positive & $+2.5-+11.0$ & 21 & $4.76^{*}$ & $+6.0-+20.0$ & 20 & $6.05 \dagger$ & $+8.0-+21.0$ & 19 & $5.26^{*}$ \\
\hline Negative & $+2.0--8.5$ & 19 & n.s. & $+5.0-\quad-8.0$ & 20 & n.s. & $+7.0-8.0$ & 21 & n.s. \\
\hline \multicolumn{10}{|c|}{ Experiment IV } \\
\hline Positive & $+5.0-+32.0$ & 31 & $10.45 \dagger$ & $+6.0-+34.0$ & 31 & $12.90 \dagger$ & $+9.5-+40.0$ & 32 & $13.78 \dagger$ \\
\hline Negative & $+4.5--12.5$ & 31 & $4.64^{*}$ & $+5.5--10.5$ & 31 & n.s. & $+8.0--16.0$ & 30 & n.s. \\
\hline \multicolumn{10}{|c|}{ Experiment V } \\
\hline Positive & $+7.0-+30.0$ & 28 & $6.04 \dagger$ & $+7.5-+30.0$ & 28 & $6.04 \dagger$ & $+9.0-+28.5$ & 27 & $5.33^{*}$ \\
\hline Negative & $+6.5--22.5$ & 26 & n.s. & $+6.5=-22.0$ & 26 & n.s. & $+8.0--20.0$ & 27 & n.s. \\
\hline
\end{tabular}

\section{RESULTS}

The general procedure for data analysis was to divide the Ss in each experiment into two TCDC groups of equal, or as close to equal as possible, size, with those shifting most in TCDC in a positive direction being designated as the "positive" TCDC shifters and those shifting negatively and/or less positively designated as the "negative" TCDC shifters. Since the change in direction, decrement or increment in RT performance, rather than magnitude, is critical for the hypothesis of this investigation, the RT change for each S was considered only from this standpoint. Thus, "positive" shifters and "negative" shifters in each experiment were then examined independently with simple one-tailed chi-square tests $(\mathrm{df}=1)$ to compare the number of Ss within each group showing an increment in RT performance over time vs those showing a decrement.

Since the possible number of measures of TCDC shift during an experiment is indeterminately large, three representative shift durations were selected as bases upon which to divide the Ss in each experiment into "positive" and "negative" shifters. These reflected change from an initial TCDC point to (1) a point just prior to task onset, to (2) a point during the task, and to (3) a point immediately following termination of task performance. Thus, in the experiments with the visual modality, TCDC shift was measured from an initial reading (Hewlett-Packard voltmeter) to three points: (1) $30 \mathrm{sec}$ before the first stimulus, (2) middle of task, and (3) final voltmeter reading. Similarly, in the two auditory modality experiments, TCDC shift was measured from the same initial reading (Hewlett-Packard voltmeter) to (1) $30 \mathrm{sec}$ before the first stimulus of Part 1, (2) $30 \mathrm{sec}$ before the first stimulus of Part 2, and (3) final reading.

In order to evaluate changes in RT performance, the RT trials for each $S$ were divided into blocks and medians were taken for each appropriate block. For the visual studies, the data were divided into blocks of 33 (Experiment I) or 32 (Experiments II and III) trials each and comparisons were made between medians of the first and last block. For the studies using auditory stimuli, a median RT value for Part 1 was obtained and for the last block of 32 trials in Part 2, thus providing, as with the other experiments, a representative change from early to late RT performance.

Table 1, a summary of the chi-square analyses, indicates that when the relatively "positive" shifters in any experiment are considered separately, changes in TCDC from an initial point in the experiment to subsequent points are significantly related to the direction of change in RT performance, with increasing positivity of TCDC change being associated more often with slowing in RT performance. For the "negative" TCDC shifters, only 2 of the 15 analyses suggested any significant decrement in RT performance, and in both cases occurred when the groups were divided with the TCDC measurements prior to task onset.

\section{DISCUSSION}

Despite variations in (1) sensory modality for stimulus presentations, (2) number of stimuli presented, and (3) difference in adaptation time for the $S$ prior to task onset, the results point to a replicable association between change in TCDC and change in disjunctive RT performance. This appears most clearly after the task has begun, and is limited in that it holds in every experiment only for the group of Ss who are relatively more positive in direction in their TCDC shifts. This latter trend is consistent with the findings for simple RT (Friedman \& Taub, 1969). However, in contrast to these findings, a study (Friedman, 1972) relating TCDC to a basic discriminatory capacity indicated that a significant relationship between TCDC and scotopic CFF could be found only in the relatively "negative" shifters of a group. It is possible that the RT tasks, long term and monotonous in nature, make somewhat different psychological demands upon Ss than did the short-term task of the CFF study, thus placing less of a premium upon the 
alertness which has been associated with "negative" shifting Ss. Rowland (1968, pp. 63-68) has pointed out the importance of the relation between "relative urgency" in observed behavior and significant shifts in cortical steady potentials, the class of potentials under which TCDC may be subsumed; and Cowen (1967b) has emphasized the importance of the psychological orientation of the $S$ to a task in a negative TCDC shift. The current findings suggest that the appearance of a relationship between the TCDC and performance may also be dependent in significant degree upon the demand value of the task itself.

It should be noted also that in both the CFF (Friedman, 1972) and simple serial RT (Friedman \& Taub, 1969) studies there was the suggestion that TCDC shifts prior to onset of the task could be a significant predictor of performance on the task. Although some results in the present study point in this direction, the more striking replicable findings suggest that with complex RT performance, the TCDC may differentiate Ss consistently only when it is based on shifts over long periods of time extending into, or the end of, performance.

In general, the significant replicable association between disjunctive RT performance and TCDC found in the present series of experiments adds to the body of empirical relationships observed between this basic bioelectric measure and fundamental parameters of human behavioral functioning.

\section{REFERENCES}

Becker, R. O., Bachman, C. H., \& Friedman, H. The direct current control system: A link between environment and organism. New York State Journal of Medicine, 1962, 62, 1169-1176.

Cowen, M. A. Elementary functional correlates of the transcephalic de circuit. Psychophysiology, 1967a, 3, 262-272.

Cowen, M. A. The baseline transephalic DC potential in normals. Journal of Psychiatric Research, 1967b, 5, 307-315.

Cowen, M A. Some higher functional correlates of the transcephalic de circuit. Psychiatric Quarterly, 1968, 42, 409-429.

Friedman, H., Becker, R. O., \& Bachman, C. H. Direct current potentials in hypnoanalgesia. Archives of General Psychiatry, 1962, 7, 193-197.

Friedman, H. \& Taub, H. A. The transcephalic DC potential and reaction time performance. Psychophysiology, 1969, 5, 504-509.

Friedman, H. The transcephalic dc potential and scotopic critical flicker frequency. Psychonomic Science, 1972, 26, 41-42.

Friedman H Becker, R. O \& Bachman, C. H. Effect of magnetic fields on reaction time. Nature, 1967, 213, 949-956.

Rowland, V. Cortical steady potential (direct current potential) in reinforcement and learning. In E. Stellar and J. M. Sprague (Eds.), Progress in physiological psychology. Vol. 2. New York: Academic Press, 1968.

(Received for publication January 2, 1973.) 